\title{
Case of Adenoid Cystic Carcinoma of Lacrimal Gland Treated by Eye Sparing Radiation Therapy using 3DCRT Technique
}

\author{
Harish Kumar* \\ Assistant professor, Department of Radiation oncology, Cancer Institute (WIA), India
}

Submission: December 31, 2019; Published: January 27, 2020

"Correspondence Author: Harish Kumar, Assistant professor, Department of Radiation oncology, Cancer Institute (WIA), India

Abstract

Adenoid cystic carcinoma compromises about $1 / 3$ of epithelial malignancies in lacrimal gland. Still now , there is no standard treatment guidelines . Mutlimodality treatment approach like Surgery and radiation are used with good results. However, the extent of surgery being a controversial issue. In regard to radio-oncology, different doses and fractionation schemes have been used in the past. We present a case of an adenoid cystic carcinoma of the left lacrimal gland successfully treated by surgery and postoperative radiation therapy.

Keywords: Orbital malignancies; Adenoid cystic carcinoma; Lacrimal tumor; Radiotherapy

Abbreviations: ACC: Adenoid Cystic Carcinoma; GTV: Gross Tumor Volume; 3DCRT: 3D Conformal Radiotherapy; PTV: Planning Target Volume; IMRT: Intensity Modulated Radiotherapy; VMAT: Volumetric Modulated Radiotherapy

\section{Case Presentation}

Adenoid Cystic Carcinomas (ACC) represents the most frequent carcinoma of the lacrimal gland with a percentage of $32 \%$ [1]. Usual Symptoms comprise, propoptosis, loss of vision, diplopia, epiphora, eye lid swelling and pain [2,3]. Local therapy as surgery or radiation therapy is complicated by the orbital anatomy involving the second, third and sixth cranial nerve and essential structures for ocular function as the lacrimal gland, external and internal muscles, lens and the retina [4]. The following case illustrates the interdisciplinary approach to a rare tumor entity and the considerations made for preserving the orbital structures functionally.

\section{Patient}

A 53 yrs -lady was evaluated for left eye proptosis for 6 months. Ophthalmic examination showed normal vision and a prominent tumor in the superior-temporal quadrant of the left orbit. MRI revealed, a left bulb protrusion due to a sharp demarcated tumor in the left upper quadrant $\left(1.8^{*} 0.7^{*} 2.0 \mathrm{~cm}\right)$ with posterior extension to lateral rectus and left lateral wall of orbit was noticed and thought to be a pleomorphic adenoma (Figure 1). The patient underwent resection of mass by left lateral orbitotomy with osteotomy of left lateral orbital wall . Intraoperatively, the tumor was found to be superficial with extracapsular extension and was consequently removed, supposedly completely.

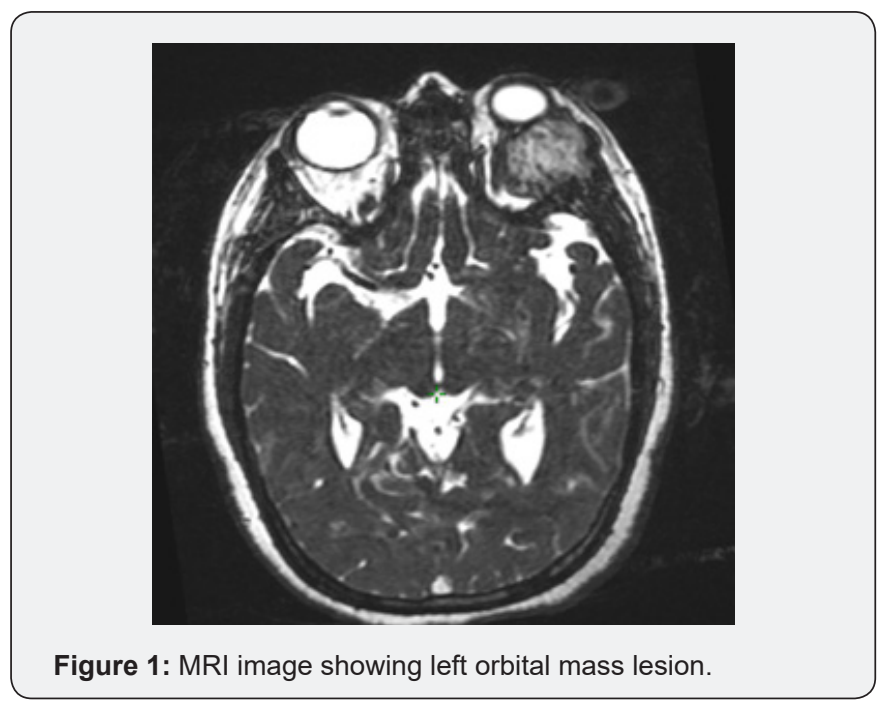

Pathological examination revealed an ACC of the lacrimal gland. No evidence of perineural invasion and the resection margins were free. Subsequently, the carcinoma was staged as pT2, pNx, cMx [5]. C Kit - Positive in Immunohistochemistry 


\section{Cancer Therapy \& Oncology International Journal}

testing. Furthermore, a postoperative MRI demonstrated thickening in post op bed suggestive of residue / post-surgical changes. Post op PET CT showed minimal asymmetric thickening in superolateral aspect of left orbit (SUV - 2.1), No other uptake elsewhere in body Chance of incomplete resection warranted a more radical operation, so orbital enucleation was advised which was rejected by the patient.

In Radiation Oncology department, the patient was thoroughly examined and counseled about postoperative radiotherapy and informed consent was obtained .Patient underwent a planning CT of the head in a supine position with a thermoplastic mask minimizing possible movements. Organs at risk were delineated using the Eclipse ${ }^{\mathrm{TM}}$ treatment planning system . To delineate the Planning Target Volume (PTV), image fusion with pre op and postoperative MRI and PET CT scan was used. Preoperative Gross Tumor Volume (GTV) was delineated and extended by an area of postoperative changes in the upper lateral quadrant of orbit considering the presuming probable residual disease medially. PTV contained this clinical target volume with a margin of $5 \mathrm{~mm}$. Anatomically, the lacrimal fossa, lateral and superior portions of the orbita were included, consistent with the literature [6]. The
PTV resembled an ellipsoid figure expanding into the eyeball and including the left optical nerve. Therefore, a main objective was to limit the radiation dose delivered to the second cranial nerve to preserve eyesight. We employed a three-step radiation plan in which the optical nerve was given a dose constraint of 55 Gy as maximum. First, 46.8 Gy were applied to the whole PTV and secondly, the second cranial nerve was blocked so dose maximum concentrated on the further tumor bed in the lateral orbit up to 54 Gy and last PTV only to post-operative bed with no margins.

RT planning was done in 3DCRT, IMRT and VMAT techniques and plan evaluation was done (Figure 2). 3DCRT plan showed a better homogenous distribution with acceptable OAR constraints. OAR dose constraints and D-max dose were compared in all the 3 techniques (Table 1). And in accordance with our dose constraints, all doses were acceptable for all organs at risk (Table 2) with homogenous uniform dose coverage in PTV with 1.08 conformity index in 3DCRT plan (Table 3). DVH distribution of all plans showed detail (Figure 3). Radiotherapy was performed by a True Beam linear accelerator (Varian Medical Systems) as a daily application of 1.8 Gy to a total dose of 60Gy delivered with $6 \mathrm{MV}$ photons.

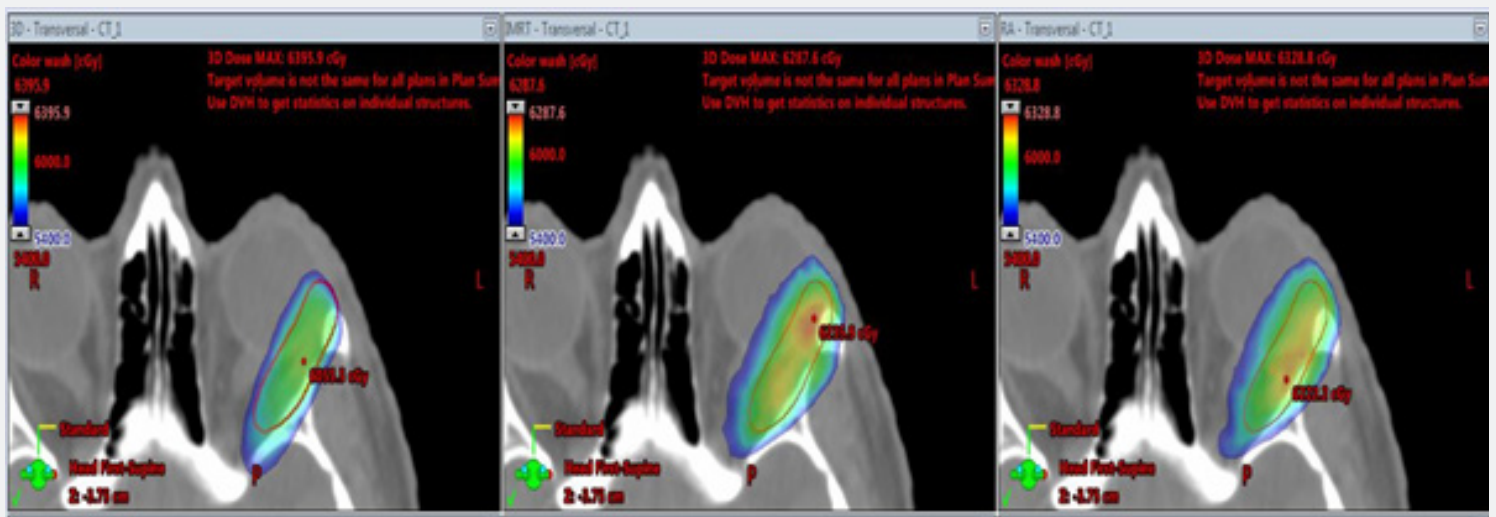

Figure 2: Isodense Coverage - Comparison of 3DCRT, Intensity Modulated Radiotherapy and Volumetric modulated Arc Therapy.

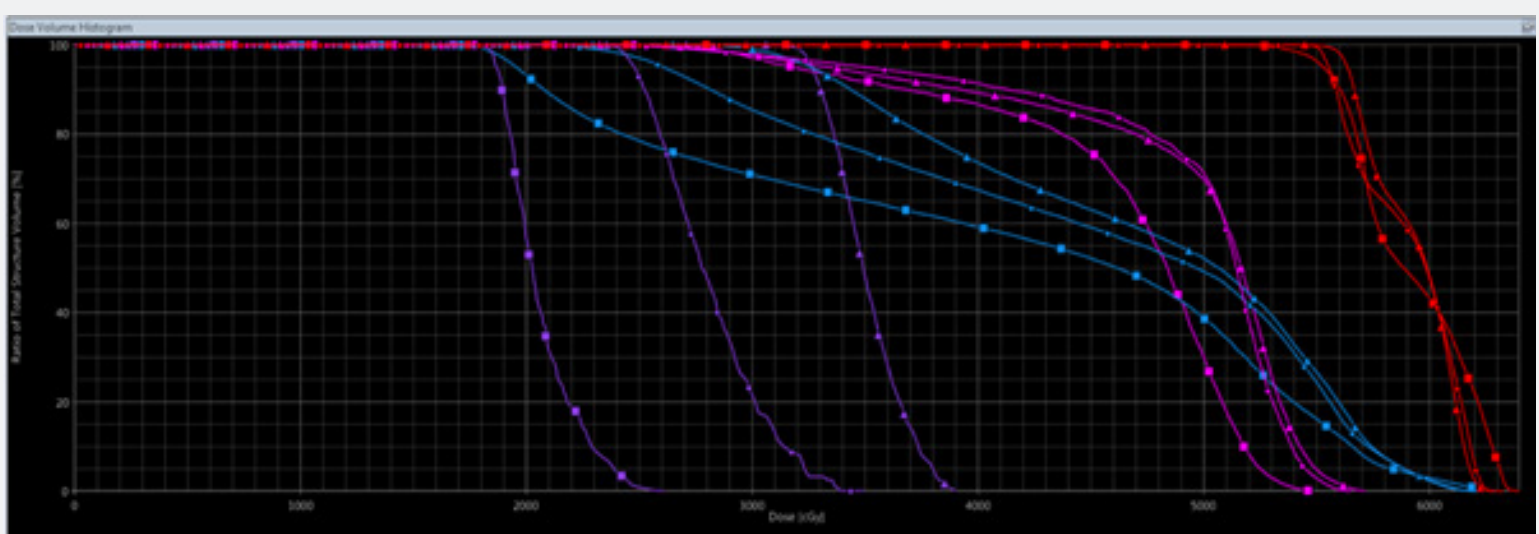

Figure 3: Comparison DVH of OAR constraints of different RT Plans - 3DCRT / IMRT / VMAT. 


\section{Cancer Therapy \& Oncology International Journal}

Table 1: PTV 60 - D max dose comparison of different plans.

\begin{tabular}{|c|c|}
\hline Technique (Max Dose) & PTV60 \\
\hline 3DCRT & 63.68 \\
\hline IMRT & 62.87 \\
\hline Rapid ARC & 63.28 \\
\hline
\end{tabular}

Table 2: Doses for organs at risk: The table illustrates the minimal (Dmin), maximal (Dmax) and mean doses (Dmean) in cGy.

\begin{tabular}{|c|c|c|c|c|}
\hline Organs & Plan & $\begin{array}{c}\text { Min Dose } \\
\text { (cGy) }\end{array}$ & $\begin{array}{c}\text { Max Dose } \\
\text { (cGy) }\end{array}$ & Mean Dose (cGy) \\
\hline Left Eye & 3DCRT & 1528.8 & 6297.3 & 4130.8 \\
\hline Left Eye & IMRT & 2563.7 & 6220.2 & 4770.3 \\
\hline Left Eye & VMAT & 1984.5 & 6212.0 & 4551.1 \\
\hline Left Lens & 3DCRT & 1824.0 & 2609.9 & 2061.7 \\
\hline Left Lens & IMRT & 3118.5 & 3907.1 & 3506.7 \\
\hline Left Lens & VMAT & 2344.1 & 3494.0 & 2809.7 \\
\hline Optic Chaisma & 3DCRT & 194.9 & 2950.1 & 2117.9 \\
\hline Optic Chaisma & IMRT & 103.5 & 1925.3 & 731.7 \\
\hline Optic Chaisma & VMAT & 611.5 & 2111.8 & 1130.7 \\
\hline Left Optic Nerve & 3DCRT & 2676.1 & 5468.4 & 4655.3 \\
\hline Left Optic Nerve & IMRT & 2387.7 & 5719.3 & 4938.8 \\
\hline Left Optic Nerve & VMAT & 2201.5 & 5651.7 & 4952.0 \\
\hline Brain Stem & 3DCRT & 22.9 & 2418.3 & 637.8 \\
\hline Brain Stem & IMRT & 20.1 & 1190.3 & 179.5 \\
\hline Brain Stem & VMAT & 20.8 & 1282.4 & 338.0 \\
\hline CTV & 3DCRT & 3194.8 & 6395.9 & 5943.3 \\
\hline CTV & IMRT & 4437.0 & 6287.6 & 5962.6 \\
\hline CTV & VMAT & 4377.5 & 6328.8 & 5944.8 \\
\hline PTV60 & 3DCRT & 6068.6 & 6368.5 & 6265.2 \\
\hline PTV60 & IMRT & 5959.0 & 6287.6 & 6145.7 \\
\hline PTV60 & VMAT & 5954.0 & 6328.8 & 6175.5 \\
\hline
\end{tabular}

Table 3: Comparison of Ipsilateral Eye, Lens and Optic nerve of different plans.

\begin{tabular}{|c|c|c|c|c|c|}
\hline Technique & $\begin{array}{c}\text { Left lens Mean dose } \\
\text { in Gy (Violet) }\end{array}$ & $\begin{array}{c}\text { Left eye } \\
\text { mean dose } \\
\text { in Gy (Blue) }\end{array}$ & $\begin{array}{c}\text { Left optic } \\
\text { neve max dose } \\
\text { in Gy (Pink) }\end{array}$ & $\begin{array}{c}\text { Max PTv } \\
\text { in Gy (Red) }\end{array}$ & $\begin{array}{c}\text { Conformity } \\
\text { Index }\end{array}$ \\
\hline 3D CRT & 20 & 41.3 & 54 & 63.9 & 1.08 \\
\hline IMRT & 35 & 47.7 & 57 & 62.8 & 1.15 \\
\hline Rapid ARC & 28 & 45.5 & 56 & 63.2 & 1.07 \\
\hline
\end{tabular}




\section{Cancer Therapy \& Oncology International Journal}

During treatment dose dependent side effects occurred as conjunctivitis, pruritus, epiphora and eyelid oedema which were addressed by moisturizing eye drops and eye drops containing sodium-hyaluronate. At the end of our treatment, periorbital hyperpigmentation and moderate pain were present without evidence of intracranial pressure. In an ophthalmological followup 1 week after radiation therapy a no deterioration of normal vision. A corneal erosion was present which was addressed by antibiotic and moisturizing eye ointment. Following RTOGcriteria, this constitutes grade 2 toxicity [7].

\section{Discussion}

ACC of the lacrimal gland is a rare disease with no established standard treatment. As most case studies only provide a limited amount of patients, the state-of-the art is yet to be found. Surgery is employed in nearly every reported case [2,3,8-14], although its extent may be doubtful. In a retrospective analysis of orbital epithelial malignancies, Polito et al. [12] revealed a prolonged survival with less extensive surgery avoiding exenterating. Additionally, Skinner et al. [15] found no evidence for survival benefit in radical surgery when compared to eye sparing surgery. Attention should be paid to the operational access as it may be contaminated with tumor cells [12].

Radiation therapy has proven to be effective in diminishing the risk for local recurrence despite no benefit in survival $[1,15]$. Of all treated patients, $54.8 \%$ underwent radiation therapy [1], mostly in a postoperative concept as this approach offers higher survival rates than a definitive treatment [16]. Disease control for incompletely resected ACC reaches 54\% with radiation therapy [8] which is important as tumor cell positive margins and perineural invasion are frequent [17]. Doses vary between 30 and 74 Gy with a preference for total doses of at least 60 Gy [2,3,8-13], which has also been applied in our case-study. Data from the literature demonstrate a 5-year survival of $25-75 \%$ after radiotherapy $[3,8,13,15]$. It may be increased by the inclusion of intra-arterial chemotherapy which requires the availability of an intact lacrimal artery [14]. In contrast to that, radiotherapy is not limited by local anatomical boundaries.

As tumor control increases, toxicity attracts attention. A dry eye symptom as described in our case report is one of the most frequent side effects of orbital radiotherapy [10]. As mentioned above, one of our key concerns was to maintain the patient's eyesight by reducing the dose to the optical nerve. In the literature, good visual capacities could be preserved in the majority of patients (68\%-91\%) $[3,8,15]$, but attention should be paid to keratitis, a serious side effect in $24 \%$ of patients in the Esmaeli study, which can lead to blindness [10]. Consequently, some authors discuss the delineation of detailed intraorbital structures as retina or sclera for toxicity evaluation [6]. It has to be kept in mind that visual impairment or blindness is a real danger of the malignancy itself, about which the patient has to be counseled. Despite that fact, high-grade toxicities (grade III or IV) are rare and may involve skin, mucous membranes, cornea and conjunctiva $[8,10,18]$.

\section{Conclusion}

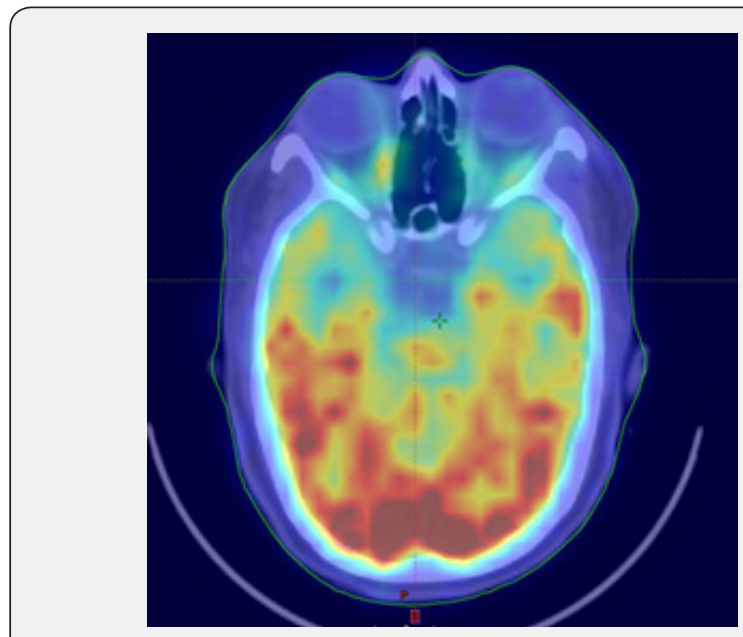

Figure 4a: PET CT done at follow up - No evidence of uptake.

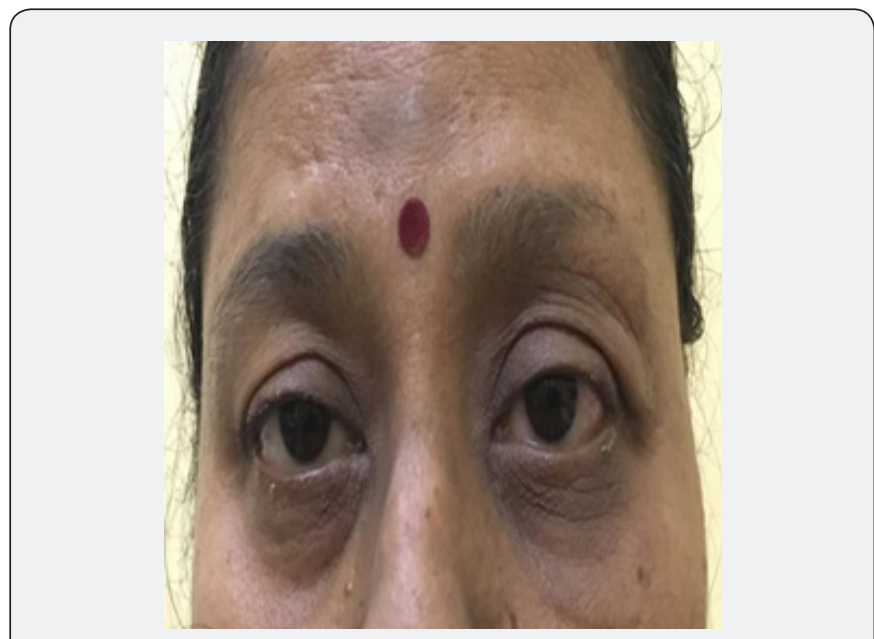

Figure 4b: Image taken at $1^{\text {st }}$ follow up -6 weeks post radiation.

The combination of eye-sparing non mutilating surgery and postoperative-radiotherapy proved to be effective. Ongoing discussions focus on the extent of surgery needed for longterm survival and the dose and fractionation of radiotherapy. This case, in accordance with the literature, suggests a dose of at least 60 Gy. IMRT and VMAT are considered the best in irradiating orbital tumours. In our case, 3DCRT plan showed a better homogenous distribution with acceptable OAR constraints and can potentially offer an improved disease control for lacrimal gland tumors with manageable acute and late side effects. First follow up PET CT showed no metabolic activity in post-operative site and ophthalmic examination showed normal visual acuity with minimal dry eye 


\section{Cancer Therapy \& Oncology International Journal}

(Figures $4 \mathrm{a}$ and $4 \mathrm{~b}$ ). Considering the ocular side effects, patients have to be counseled thoroughly as an impairment of eyesight might be a possible long-term complication of treatment (Figure 5). Therefore, all attempts should be undertaken to reduce toxicity and improve patient's quality of life.

\section{Technique Symbol}

\section{DCRT}

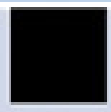

\section{IMRT}

\section{RAPID ARC}

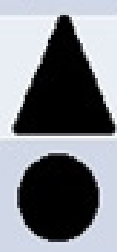

Figure 5: Technique and Symbol.

\section{References}

1. Mallen-St Clair J, Arshi A, Tajudeen B, Abemayor E, St John M (2014) Epidemiology and treatment of lacrimal gland tumors: a populationbased cohort analysis. JAMA Otolaryngol Head Neck Surg 140(12): 1110-1116.

2. Roshan V, Pathy S, Mallick S, Chander S, Sen S, Chawla B (2015) Adjuvant Radiotherapy with Three-Dimensional Conformal Radiotherapy of Lacrimal Gland Adenoid Cystic Carcinoma. J Clin Diagn Res 9(10): 0507.

3. Natanegara IAAA, Koornneef L, Veenhof K, Gonzáles Gonzáles D, Boukes RJ (1990) An alternative approach for the management of adenocystic carcinoma of the lacrimal gland. Orbit 9(2): 101-105.

4. Kahle, Werner, Frotscher, Michael (2005) Taschenatlas Anatomie in 3 Bänden - Nervensystem und Sinnesorgane, $\left(9^{\text {th }}\right.$ ed), Georg Thieme Verlag, Stuttgart.

5. Edge SB, Compton CC (2010) American Joint Committee on Cancer: the $7^{\text {th }}$ edition of the AJCC cancer staging manual and the future of TNM. Ann Surg Oncol 17(6): 1471-1474.
6. Orlandi E, Takanen S, Giandini T, Iannacone E, Fontanella W, et al (2014) Postoperative radiotherapy with volumetric modulated arc therapy of lacrimal gland carcinoma: two case reports and literature review. Future Oncol Lond Engl 10(14): 2111-2120.

7. Cox JD, Stetz J, Pajak TF (1995) Toxicity criteria of the Radiation Therapy Oncology Group (RTOG) and the European Organization for Research and Treatment of Cancer (EORTC). Int J Radiat Oncol Biol Phys 31(5): 1341-1346.

8. Brada M, Henk JM (1987) Radiotherapy for lacrimal gland tumours. Radiother Oncol J Eur Soc Ther Radiol Oncol 9(3): 175-183.

9. Ducrey N, Villemure JG, Jaques B (2002) Cystic adenocarcinomas of the lacrymal gland. Klin Monatsblätter Für Augenheilkd 219(4): 231-234.

10. Esmaeli B, Yin VT, Hanna EY, Kies MS, William WN, et al. (2016) Eyesparing multidisciplinary approach for the management of lacrimal gland carcinoma. Head Neck 38(8): 1258-1262.

11. Manousaridis K, Stropahl G, Hingst V, Guthoff R (2011) Adenoid cystic carcinoma of the lacrimal gland: report of two cases and literature review. Klin Monatsblätter Für Augenheilkd 228(1): 54-56.

12. Polito E, Leccisotti A (1993) Epithelial malignancies of the lacrimal gland: survival rates after extensive and conservative therapy. Ann Ophthalmol 25(11): 422-426.

13. Sanders JC, Mendenhall WM, Werning JW (2016) Adenoid cystic carcinoma of the lacrimal gland. Am J Otolaryngol 37(2): 144-147.

14. Tse DT, Kossler AL, Feuer WJ, Benedetto PW (2013) Long-term outcomes of neoadjuvant intra-arterial cytoreductive chemotherapy for lacrimal gland adenoid cystic carcinoma. Ophthalmology 120(7): 1313-1323.

15. Skinner HD, Garden AS, Rosenthal DI, Ang KK, Morrison WH, et al. (2011) Outcomes of malignant tumors of the lacrimal apparatus: the University of Texas MD Anderson Cancer Center experience. Cancer 117(12): 2801- 2810.

16. Wright JE, Rose GE, Garner A (1992) Primary malignant neoplasms of the lacrimal gland. Br J Ophthalmol 76(7): 401-407.

17. Lin YC, Chen KC, Lin CH, Kuo KT, Ko JY, et al. (2012) Clinicopathological features of salivary and non-salivary adenoid cystic carcinomas. Int J Oral Maxillofac Surg 41: 354-360.

18. Hoppe BS, Wolden SL, Zelefsky MJ, Mechalakos JG, Shah JP, et al. (2008) Postoperative intensity-modulated radiation therapy for cancers of the paranasal sinuses, nasal cavity, and lacrimal glands: technique, early outcomes, and toxicity. Head Neck 30(7): 925-932. 
(ब) (1)

This work is licensed under Creative Commons Attribution 4.0 License DOI: 10.19080/CTOIJ.2020.15.555916

\section{Your next submission with Juniper Publishers} will reach you the below assets

- Quality Editorial service

- Swift Peer Review

- Reprints availability

- E-prints Service

- Manuscript Podcast for convenient understanding

- Global attainment for your research

- Manuscript accessibility in different formats ( Pdf, E-pub, Full Text, Audio)

- Unceasing customer service

Track the below URL for one-step submission https://juniperpublishers.com/online-submission.php 